\title{
Benchmarking of HEU mental annuli critical assemblies with internally reflected graphite cylinder
}

\author{
Liu Xiaobo ${ }^{1, \text { a }}$, John D. Bess ${ }^{2}$, and Margaret A. Marshall ${ }^{2}$ \\ 1 Institute of Nuclear Physics and Chemistry, CAEP, PO Box 919-210, Mianyang, Sichuan 621900, China \\ 2 Idaho National Laboratory, PO Box 1625, MS 3855, Idaho Falls, Idaho 83415, USA
}

\begin{abstract}
Three experimental configurations of critical assemblies, performed in 1963 at the Oak Ridge Critical Experiment Facility, which are assembled using three different diameter HEU annuli (15-9 inches, 15-7 inches and 13-7 inches) metal annuli with internally reflected graphite cylinder are evaluated and benchmarked. The experimental uncertainties which are 0.00057, 0.00058 and 0.00057 respectively, and biases to the benchmark models which are $-0.00286,-0.00242$ and -0.00168 respectively, were determined, and the experimental benchmark $\mathrm{k}_{\text {eff }}$ results were obtained for both detailed and simplified models. The calculation results for both detailed and simplified models using MCNP6-1.0 and ENDF/B-VII.1 agree well to the benchmark experimental results within difference less than $0.2 \%$. The benchmarking results were accepted for the inclusion of ICSBEP Handbook.
\end{abstract}

\section{Introduction}

An extensive series of delayed critical experiments were performed at the Oak Ridge Critical Experiments Facility (ORCEF), using high enriched uranium (HEU) metal during the 1960s and 1970s in support of criticality safety operations at the Y-12 Plant. These experiments were designed to evaluate the storage, casting, and handling limits of the Y-12 Plant and to provide data for the verification of cross sections and calculation methods utilized in nuclear criticality safety applications.

Many of these experiments have already been evaluated and included in the International Handbook of Evaluated Criticality Safety Benchmark Experiments (ICSBEP Handbook [1]): unreflected cylinder (HEU-MET-FAST-051), 1 and 2 inch-thick graphitereflected (HEU-MET-FAST-071), polyethylene-reflected (HEU-MET-FAST-076), and beryllium-reflected [2] (HEUMET-FAST-059 and HEU-MET-FAST-069), and one case of HEU metal annuli surrounding potassium-filled, stainless steel cans was included in IRPhEP Handbook [3] (ORCEF-SPACE-EXP-001).

In this paper another three experimental configurations of critical assemblies, which are internal graphite reflected metal uranium assemblies with three different diameter HEU annuli (15-9 inches, 15-7 inches and 13-7 inches) are taken to evaluate the experimental uncertainty and bias, and to benchmark the detailed and simplified model for further inclusion of ICSBEP Handbook [1]. These experiments can be found in Reference [4] and in their associated logbook [5].

Firstly, the experimental uncertainties were analyzed, then the experimental biases were determined, at last the benchmark models were developed for both detailed and simplified configurations. The calculation results agree to

\footnotetext{
a e-mail: liu_express11@yahoo.com
}

the benchmark experimental results within difference less than $0.2 \%$ (equivalently less than 3 times of experimental $1 \sigma$ uncertainty). The benchmarking results for these three critical configurations were accepted for inclusion of ICSBEP Handbook.

\section{Evaluation of uncertainties and biases}

\subsection{Descriptions of assemblies}

These experiments were performed on a vertical assembly machine previously described by Rohrer et al. [6]. The assemblies were coaxial high enriched uranium metal (HEU) annuli with outside diameters varying in two-inch steps from 11 to 15 inches and the inside diameters varying in two-inches steps from 7 to 9 inches, and had only internal graphite cylinder without reflector. The sketch map of vertical cross-section view for case 1 is shown in Fig. 1.

Each assembly comprised of two sections: lower and upper section, of which the lower one was supported on a low-mass support stand and the upper section was mounted on a 0.010-inch-thick stainless steel diaphragm. The radial alignment for each assembly were performed with level to the accuracy of $\pm 0.001 \mathrm{inch}$. The lower section was raised until it made contact with the diaphragm and actually slightly lifted the upper section of material mounted on the diaphragm and then the reactivity was measured. The reactivity worth of each parts of the support structure was measured by perturbation experiments respectively, then the reactivity of each "clean" assembly was obtained.

The basic information and measured reactivity for the three cases was summarized in Table 1. 


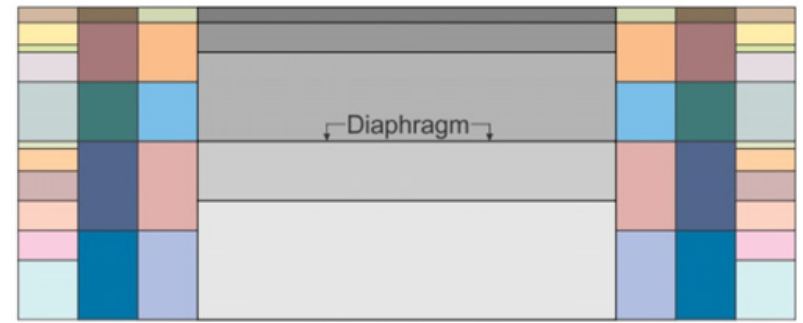

Figure 1. Sketch map for case 1 (Grey color refers to graphite cylinder).

Table 1. Basic information of assemblies.

\begin{tabular}{|c|c|c|c|c|c|}
\hline \multirow{2}{*}{ Case } & \multicolumn{3}{|c|}{ Nominal Dimensions (in.) } & \multirow{2}{*}{$\begin{array}{l}\text { Internal } \\
\text { Material }\end{array}$} & \multirow{2}{*}{ 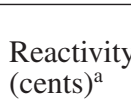 } \\
\hline & OD & ID & Height & & \\
\hline 1 & 15 & 9 & $55 / 16$ & graphite & -11.5 \\
\hline 2 & 15 & 7 & $41 / 16$ & graphite & -24.7 \\
\hline 3 & 13 & 7 & $51 / 4$ & graphite & +15.6 \\
\hline
\end{tabular}

(a) Measured reactivity values are for the assembled experiment corrected for support structure. These values can be converted to $\mathrm{k}_{\text {eff }}$ by using an effective delayed-neutron fraction of 0.0066 .

\subsection{Experimental uncertainty analysis}

Uncertainties are evaluated using two approaches. Measured data are used where sufficient experimental information is available to analyze the uncertainties. Where experimental data are not available, Monte Carlo calculations were performed using the Monte Carlo NParticle (MCNP) versions 6-1.0 [7] and ENDF/B-VII.1 [8] neutron cross section libraries.

For the last approach the bounding uncertainties and $1 \sigma$ uncertainties for each of parameter were determined, and then the perturbations were introduced into MCNP model to calculate the uncertainties respectively. When the change in $\mathrm{k}_{\text {eff }}$ between the base case and the perturbed model (single-sided perturbation), or two perturbed models (double-sided perturbation directly comparing an upper and a lower perturbation from the base case), is less than the statistical uncertainty of the Monte Carlo results, the changes in the variable are amplified by scaling factor (SF), if possible. The resulting calculated change is then scaled to a value corresponding to the given uncertainty divided by SF, assuming linearity, which should be adequate for these small changes in $\mathrm{k}_{e f f}$. For double-sided perturbation with scaling factor, this method is equated as following:

$$
\Delta k_{\text {eff }}(1 \sigma)=\frac{\left|k_{\text {upper }}-k_{\text {lower }}\right|}{2 \times S F}
$$

where $k_{\text {upper }}$ and $k_{\text {lower }}$ stand for the $\mathrm{k}_{\text {eff }}$ of perturbed models with an upper and a lower perturbation from the base model, respectively.

Sometimes, to find the effect of one kind of parameter on the $\mathrm{k}_{\text {eff }}$ value (which is assumed to be negligible based on evaluator experience), this parameter from several similar parts was perturbed simultaneously and the combination of the uncertainty should be decoded for accounting for this circumstance. This is the case such as diameter, mass of HEU annuli parts for the all three configurations.
Table 2. Experimental uncertainty.

\begin{tabular}{|c|c|c|c|}
\hline \multirow{2}{*}{ Perturbed Parameter } & \multicolumn{3}{|c|}{$\Delta \mathrm{k}_{e f f}$} \\
\hline & Case 1 & Case 2 & Case 3 \\
\hline Temperature (K) & 0.00004 & 0.00004 & 0.00004 \\
\hline Reproducibility (c) & 0.00013 & 0.00013 & 0.00013 \\
\hline Measured reactivity $(c)$ & 0.00046 & 0.00046 & 0.00046 \\
\hline$\beta_{e f f}$ & 0.00005 & 0.00005 & 0.00005 \\
\hline HEU stack height $(\mathrm{cm})^{\mathrm{a}}$ & 0.00003 & 0.00003 & 0.00003 \\
\hline${ }^{234} \mathrm{U}$ content (wt.\%) & 0.00003 & 0.00004 & 0.00003 \\
\hline${ }^{235} \mathrm{U}$ content (wt.\%) & 0.00019 & 0.00019 & 0.00019 \\
\hline${ }^{236} \mathrm{U}$ content (wt.\%) & $\mathrm{NEG}^{\mathrm{b}}$ & 0.00003 & NEG \\
\hline Uranium impurities (ppm) & 0.00025 & 0.00025 & 0.00022 \\
\hline Graphite impurities (ppm) & NEG & 0.00004 & NEG \\
\hline Graphite arrangement & N/A & N/A & 0.00006 \\
\hline $\begin{array}{l}\text { Total } \\
\text { Experimental Uncertainty }\end{array}$ & 0.00057 & 0.00058 & 0.00057 \\
\hline
\end{tabular}

The uncertainty from experiment, dimensions and displacement, mass, isotopic content and impurities are evaluated respectively and all the uncertainties for the three cases are summarized in Table 2.

The total experimental uncertainties for the three configurations are $0.00057,0.00058$ and 0.00057 respectively, in which the uncertainty from experiment itself accounts for most (more than 70\%) contributions, otherwise the uncertainty from dimensions and mass accounts for almost negligible contribution due to high accurate manufacturing process and measuring.

\subsection{Experimental bias analysis}

Bias analysis included the effect of room return and air, temperature, the bias of removing the support structures, homogenization of the HEU annuli and graphite cylinder, and the removal of material impurities.

The same to uncertainty analysis, biases are also evaluated using two approaches. Measured data are used where sufficient experimental information is available to determine the correction. Where experimental data are not available, Monte Carlo calculations were performed using MCNP6-1.0 and ENDF/B-VII.1 neutron cross section libraries by comparing the benchmark models to a model with no simplifications.

Results of all the biases for both the detailed and simplified benchmark model are summarized in Table 3 .

\section{Benchmark results}

The experiment benchmark $\mathrm{k}_{\text {eff }}$ for both detailed and simplified model can be obtained through the above uncertainty and bias analysis and the results are provided in Table 4.

The calculated results for both detailed and simplified benchmark models, using MCNP6-1.0 and ENDF/B-VII.1 neutron cross section libraries, are summarized in Table 5, 
Table 3. Experimental bias.

\begin{tabular}{|c|c|c|c|}
\hline \multirow{2}{*}{ Bias/Correction } & \multicolumn{3}{|c|}{$\Delta \mathrm{k}_{e f f}$} \\
\hline & Case 1 & Case 2 & Case 3 \\
\hline $\begin{array}{l}\text { 1. Room Return } \\
\text { and Air }\end{array}$ & -0.00117 & -0.00125 & -0.00094 \\
\hline $\begin{array}{l}\text { 2. Removal of } \\
\text { Stainless Steel } \\
\text { Diaphragm }\end{array}$ & 0.00068 & 0.00108 & 0.00077 \\
\hline $\begin{array}{l}\text { 3. Removal of } \\
\text { Diaphragm } \\
\text { Support Ring }\end{array}$ & -0.00042 & -0.00038 & -0.00032 \\
\hline $\begin{array}{l}\text { 4. Removal of } \\
\text { Support Structure }\end{array}$ & -0.00088 & -0.00133 & -0.00065 \\
\hline 5. Temperature & NEG & NEG & NEG \\
\hline $\begin{array}{l}\text { 6. Homogenization } \\
\text { of Graphite } \\
\text { Cylinder }\end{array}$ & -0.00035 & -0.00003 & -0.00015 \\
\hline $\begin{array}{l}\text { 7. Removal of } \\
\text { Graphite Impurities }\end{array}$ & -0.00002 & -0.00007 & 0.00000 \\
\hline $\begin{array}{l}\text { 8. Homogenization of } \\
\text { HEU Annuli }\end{array}$ & -0.00070 & -0.00043 & -0.00039 \\
\hline $\begin{array}{l}\text { 9. Removal of HEU } \\
\text { Impurities }\end{array}$ & 0.00000 & 0.00000 & 0.00000 \\
\hline $\begin{array}{l}\text { Total Bias } \\
\quad \text { for Detailed Model }\end{array}$ & -0.00179 & -0.00189 & -0.00114 \\
\hline $\begin{array}{l}\text { for Simplified } \\
\text { Model }^{\mathrm{b}}\end{array}$ & -0.00286 & -0.00286 & -0.00286 \\
\hline
\end{tabular}

(a) Bias is the arithmetic sum of Items 1 through 5; bias uncertainty is 0.00006 for all the three cases.

(b) Bias is the arithmetic sum of Items 1 through 9; bias uncertainty is 0.00013 for all the three cases.

which agree well to the benchmark experimental results within difference less than $0.2 \%$ (equiva lently less than 3 times of experimental $1 \sigma$ uncertainty) and accepted for inclusion of ICSBEP Handbook.

\section{Conclusions}

Three experimental configurations of critical assemblies, HEU annuli (15-9 inches, 15-7 inches and 13-7 inches) metal annuli with internally reflected graphite cylinder, are evaluated and benchmarked. The experimental uncertainties and biases were determined, and the experimental benchmark $\mathrm{k}_{\text {eff }}$ results were obtained for both detailed and simplified model.

The calculation results for both detailed and simplified models using MCNP6-1.0 and ENDF/B VII.1 agree well to the benchmark experimental results within difference less than $0.2 \%$. The three configurations are accepted for inclusion of ICSBEP Handbook.
Table 4. Experiment benchmark results.

\begin{tabular}{lccccccc}
\hline \multirow{2}{*}{ Case } & \multicolumn{3}{c}{ Detailed Model } & \multicolumn{3}{c}{ Simplified Model } \\
\cline { 2 - 7 } & $\mathrm{k}_{\text {eff }}$ & \pm & $\sigma$ & $\mathrm{k}_{\text {eff }}$ & \pm & $\sigma$ \\
\hline 1 & 0.9981 & \pm & 0.0006 & 0.9970 & \pm & 0.0006 \\
2 & 0.9971 & \pm & 0.0006 & 0.9966 & \pm & 0.0006 \\
3 & 1.0001 & \pm & 0.0006 & 0.9995 & \pm & 0.0006 \\
\hline
\end{tabular}

Table 5. Calculation results.

\begin{tabular}{|c|c|c|c|c|}
\hline \multirow{2}{*}{ Case } & \multicolumn{2}{|c|}{ Calculation of Model } & \multicolumn{2}{|c|}{$(\mathrm{C}-\mathrm{E}) / \mathrm{E} \%$} \\
\hline & Detailed & Simplified & Detailed & Simplified \\
\hline 1 & $0.9970 \pm 0.0006$ & $0.99784 \pm 0.00004$ & -0.08 & 0.08 \\
\hline 2 & $0.9966 \pm 0.0006$ & $0.99619 \pm 0.00004$ & -0.08 & -0.04 \\
\hline 3 & $0.9995 \pm 0.0006$ & $0.99911 \pm 0.00004$ & -0.12 & -0.04 \\
\hline
\end{tabular}

This work was funded by CSC (China Scholarship Council) via the visiting scholarship exchanging program. This paper was prepared at the Idaho National Laboratory for the U.S. Department of Energy under Contract Number (DEAC0705ID14517).

The author would like to acknowledge J. Blair Briggs at Idaho National Laboratory and John Mihalczo at Oak Ridge National Laboratory.

\section{References}

[1] International Handbook of Evaluated Criticality Safety Benchmark Experiments (ICSBEP), Report NEA/NSC/DOC (95)03/I-IX, (OECD-NEA, Paris) (2012)

[2] John D. Bess. Benchmark Evaluation of Uranium Metal Annuli and Cylinders with Beryllium Reflectors. Transaction of ANS 102, 273-374

[3] International Handbook of Evaluated Reactor Physics Benchmark Experiments (IRPhEP), Report NEA/NSC/DOC (2006)1, (OECD-NEA, Paris) (2013)

[4] J.T. Mihalczo, Graphite and Polyethylene Reflected Uranium Metal Cylinders and Annuli, Union Carbide Corporation, Nuclear Division Report Y-DR-81 (1972)

[5] ORNL logbook 12R(East cell-logbook1, E-19) on page 72-84, 123-127, and 135-139

[6] E.R. ROHRER et al., Neutron Phys. Div. Ann. Progr. Rept. Sept. 1, 1961, ORNL-3193, p. 168, Oak Ridge National Laboratory (1961)

[7] Forrest Brown, Brian Kiedrowski, Jeffrey Bull, MCNP5-1.60 Release Notes, LA-UR-10-06235 (2010)

[8] M.B. Chadwick, et al., ENDF/B-VII.1: Nuclear Data for Science and Technology: Cross Sections, Covariances, Fission Product Yields and Decay Data, Nucl. Data Sheets 112, 2887-2996 (2011) 